\title{
Resgatando a classe sob as lentes do materialismo histórico
}

\author{
Redeeming class under the lens of historical materialism
}

Resenha do livro: MATTOS, Marcelo Badaró. A classe trabalhadora: de Marx ao nosso tempo. São Paulo: Boitempo, 2019.

Palavras-chave: classe trabalhadora; materialismo histórico; marxismo.

Keywords: working class; historical materialism; marxism.

\section{Victor Pastore*}

O NOVO LIVRO DO HISTORIAdOR Marcelo Badaró Mattos, A classe trabalhadora: de Marx ao nosso tempo, reúne muitas de suas reflexões teóricas publicadas nos últimos anos em diversos artigos e livros e que agora ganham unidade em uma exposição consistente e substanciosa. A principal preocupação do autor na obra é defender a validade e atualidade do aparato conceitual marxista - sobretudo da categoria de "classes sociais" e seus desdobramentos em "classe trabalhadora" (ou "proletariado") e "luta de classes" - para a análise tanto da sociedade capitalista contemporânea quanto de sua história.

Por vezes criticadas como mecanicistas, oriundas de determinismo econômico, ou apontadas como insuficientes para tratar das múltiplas experiências e identidades dos sujeitos históricos, ou ainda tidas como desatualizadas para pensar um suposto contexto de "fim do trabalho" e do mundo fabril, as elaborações de Marx e Engels sobre as classes sociais têm perdido terreno nas últimas décadas. Como o próprio autor aponta, há anos categorias como "burguesia", "classe dominante", "classe trabalhadora" e "proletariado" saíram do vocabulário corrente no senso comum e das mídias hegemônicas, mas também perdem espaço paulatinamente no mundo acadêmico, onde foram dominantes até pelo menos a década de 1980. Em seu lugar, noções de classe que confundem-se com renda, consumo e status circulam socialmente, muitas vezes expressas através de letras que hierarquizam indivíduos dos mais ricos aos mais pobres e mascaram o antagonismo fundamental da sociedade capitalista, entre burguesia e classe trabalhadora. No Brasil, setores da própria esquerda contribuíram com esse processo ao validar análises entusiasmadas como a da emergência

Mestrando em História Social pela FFLCH-USP, com financiamento da Fundação de Amparo à Pesquisa do Estado de São Paulo (FAPESP). ORCID: https://orcid.org/0000-0003-2180-4879. E-mail: vpastore22@gmail.com. 
de uma "nova classe média" pautada pelo consumo e ascensão de indivíduos da "Classe D" para a "Classe C", no anseio de chancelar políticas de Estado.

Ao propor o resgate das categorias centrais da obra de Marx e, em menor medida, de Engels, demonstrando sua validade empírica para o entendimento da realidade concreta atual, bem como para o estudo do passado, Mattos busca dar uma resposta àquela situação. Para isso, estruturou sua obra em quatro capítulos em que trata, respectivamente, da explicação dos conceitos na obra dos autores e o contexto de seu surgimento; da situação da classe trabalhadora no século XXI, no Brasil e no mundo, e de que maneira aqueles conceitos ainda são verificados; da refutação de teses que, tanto no âmbito das ciências sociais quanto no da história, buscaram negar o arcabouço teórico marxista. Nesse último ponto, correspondente aos capítulos três e quatro, Mattos considera também as boas contribuições aos conceitos e teorias sobre classes elaboradas por outros pensadores que, sem negar Marx e Engels, partiram deles e avançaram em suas análises.

Considero este um dos méritos do autor: ao não esposar uma perspectiva dogmática ou reivindicar cegamente o arsenal marxista como algo suficiente e acabado em si mesmo, Mattos demonstra o potencial daquele pensamento como uma base ou um "ponto de partida" que foi, inclusive, muito aprofundado pelos representantes do que o autor chamou de "tradição de crítica ativa do materialismo histórico". Seguiram nessa linha pensadores como Antonio Gramsci; os consagrados autores da História Social Inglesa, a exemplo de E. P. Thompson e Eric Hobsbawm; os expoentes da atual História Global do Trabalho, como Marcel van der Linden, Marcus Rediker e Peter Linebaugh; além de sociólogos como Ruy Braga e Ricardo Antunes.

No primeiro capítulo, cerne da obra, o autor apresenta todo o aparato conceitual com o qual trabalha e faz referência no restante dos capítulos. Portanto, nesta resenha dedico um pouco mais de espaço a tal parte do que às demais. Nela, em consonância com as atuais posições da Sociologia e da História Social do Trabalho, as quais pensam o conceito de classe trabalhadora de forma ampliada, não restrita ao operário fabril ou ao assalariamento, Mattos resgata os textos dos fundadores do materialismo histórico para mostrar que essa noção já estava indicada lá - sobretudo nos escritos de caráter mais político e conjuntural, em que abordaram a luta dos explorados nas diversas regiões periféricas do mundo, que não estavam no estágio mais consolidado do capitalismo industrial.

Mattos entende que Marx e Engels propuseram uma noção de classe como relação social, estruturada em torno da produção e reprodução da vida, que se forma no decorrer da história. Nessa lógica, a classe trabalhadora é produto de um processo de expropriação em que a única coisa que lhe sobra é a força de trabalho. Tal situação coloca esses indivíduos em oposição a outros e, a partir dessa luta, passam a se identificar enquanto sujeitos coletivos, tomando consciência enquanto classe.

Portanto, o autor tem a preocupação de mostrar como a noção de classe naqueles pensadores não se restringia ao conteúdo ou forma do trabalho. Engessada posteriormente tanto por teóricos quanto por líderes de governo que reivindicaram a tradição marxista - dentro do termo "classe operária", a categoria foi instrumentalizada durante certo tempo de modo a retirar a agência e a potencialidade de sujeito revolucionário de vários grupos de trabalhadores, todos submetidos à exploração do capital, de uma forma ou de outra-escravizados, domésticos, terceirizados, autônomos, meeiros, informais etc. Segundo Mattos, a perspectiva de Marx e 
Engels sobre os trabalhadores já era global e articulada, ainda que suas análises tenham se concentrado no proletariado britânico, no local de ponta do capitalismo. Por isso, enxergaram as diversas "frações de classe" que representam diferentes experiências dinâmicas pelas quais os trabalhadores podem ou não transitar ao longo de sua vida.

Marcelo Badaró Mattos considera os debates atuais nos movimentos sociais e na academia e aborda essa heterogeneidade também em termos de raça, gênero e outros recortes que representam as distintas experiências históricas de opressão e alienação dos sujeitos. Entendendo que essas noções decorrem de relações concretas dentro da totalidade e proporcionam distintas formas de subjetividade, Mattos defende que o marxismo não pode ignorá-las ou relegá-las a segundo plano. Afinal,

tratar da heterogeneidade que atravessa a classe, que pode até mesmo alimentar formas de preconceito e opressões, é um desafio inevitável para quem sustenta a validade analítica do conceito de classe trabalhadora e tanto mais para quem aposta na potencialidade transformadora desse sujeito histórico. ${ }^{1}$

Sem ignorar as limitações da obra de Marx e Engels nessas temáticas, o autor indica algumas de suas reflexões que abriram caminho para novas teorias sobre a articulação do capital com tais opressões - por exemplo, as teorias das feministas marxistas que destacaram a reprodução social, trabalho não pago desempenhado principalmente por mulheres, como central no rebaixamento do custo da força de trabalho diretamente envolvida no processo de produção. Essas interpretações não desconsideram o aspecto de classe, mas compreendem que ele atravessa e é atravessado pelas outras opressões, as quais se tornam parte integral da sociedade capitalista ao longo do processo histórico. No fim, seu argumento é que "reconhecer a heterogeneidade, a diversidade e a dinâmica histórica do sujeito coletivo classe trabalhadora, sem perder de vista sua existência como unidade relacional, é um desafio para o qual acredito que estejamos mais bem acompanhados com Marx". ${ }^{2}$

Outro problema que Mattos enfrenta ainda no primeiro capítulo é a subjetividade da classe trabalhadora, a consciência de classe, pensada como algo que não é determinado mecanicamente pela posição dos indivíduos nas relações de produção. Para isso, articula o conceito marxista de ideologia com as contribuições de Gramsci, demonstrando que a consciência de classe, ou a percepção de si enquanto sujeito histórico integrante de um coletivo expropriado, só pode ser criada a partir da ruptura com a ideologia da classe dominante, que tem hegemonia no senso comum. O desafio para os movimentos da classe trabalhadora sempre será proporcionar esse rompimento ou emancipação, num mundo onde os trabalhadores encontram-se alienados.

No segundo capítulo, o autor fornece um compilado consistente de dados sobre a composição da força de trabalho na contemporaneidade. Além de informações globais, ele trata de casos particulares como a Alemanha, os Estados Unidos, a Índia, a China e, atendendo ao interesse de seu principal público leitor, o Brasil. Suas conclusões básicas são que vivemos em um mundo cada vez mais urbanizado, que não prescinde do trabalho fabril - apesar de este ter migrado da Europa Ocidental -, que a concentração do capital

1 MATTOS, Marcelo Badaró. A classe trabalhadora: de Marx ao nosso tempo. São Paulo: Boitempo, 2019, p. 58.

2 Ibidem, p. 147. 
continua, com o aumento da produtividade combinado a poucos ganhos salariais, validando a proposição marxista da lógica de acumulação do sistema, baseado na exploração do mais-valor. Além disso, identifica que o mercado de trabalho, em escala mundial, tem sido marcado pela crescente precariedade das relações de trabalho, com destaque para a terceirização. Aquilo que foi considerado como modelo padrão de "trabalho formal", representado por funcionários assalariados, estáveis e com direitos, foi mera exceção do pós-guerra europeu para os trabalhadores homens, jamais uma regra.

Finalmente, nos dois últimos capítulos, Mattos utiliza todo o pensamento teórico sistematizado no primeiro e os dados da situação atual apresentados no segundo para mostrar a inconsistência de análises sociológicas e historiográficas que afirmaram o "fim da classe trabalhadora" ou sua invalidez enquanto categoria analítica. Geralmente eurocêntricas ou fundamentadas em teorias da virada linguística - em que "classe seria realidade discursiva e não ontológica" ${ }^{-}$, essas análises partiram mais de caricaturas do pensamento marxiano, ou de intelectuais que reivindicaram Marx, do que de uma leitura cuidadosa de seus textos.

Acredito que a principal contribuição nessas duas partes são as reflexões a respeito das novas categorias acadêmicas usadas para analisar os mundos do trabalho. Na sociologia tem-se, por exemplo, a ideia do "precariado" como uma nova classe, não apenas uma fração da classe trabalhadora, enquanto a historiografia propôs uma classe dos "trabalhadores subalternos", para enfatizar a diversidade de todos os sujeitos submetidos à mercantilização da força de trabalho, dissociando o conceito da forma de trabalho livre assalariado.

A posição do autor, em geral, é de que a classe trabalhadora na obra de Marx e Engels já é ampla e inclusiva o bastante, sem que se torne necessário aderir a certas novidades conceituais. Porém, percebe aspectos positivos em ambos os casos, destacando diálogos críticos que os intelectuais recentes estabeleceram com o materialismo histórico, sobretudo os que foram protagonizados pelos representantes da chamada História Global do Trabalho, os quais têm chamado atenção para a diversidade de formas de exploração ao redor do globo, considerando-as interconectadas transnacionalmente a um mesmo processo de subsunção do trabalho.

Ressalta-se que a obra em questão é apresentada de forma bastante didática, com a preocupação de situar o leitor a todo o momento nas categorias da obra marxiana - tais como "exército industrial de reserva", "ideologia", "trabalho produtivo e improdutivo", "acumulação primitiva" -, bem como nos contextos em que surgiram ou se inseriram. Longe de tornar as discussões do livro simplistas, como o próprio Mattos faz questão de negar, esse fator concede ao texto a possibilidade de ser um excelente guia para os recém-ingressados na seara do marxismo.

Por fim, considero o livro muito além de uma mera empreitada acadêmica, pois tem potencial para incidir no debate político atual. Em um contexto de extrema precarização do trabalho, dessindicalização, retrocessos de direitos, descrença generalizada nas "utopias", ao mesmo tempo em que a produtividade do trabalho aumenta, gerando altos lucros para a burguesia e nenhuma distribuição dos ganhos, a obra torna-se imprescindível ao assumir que a classe trabalhadora ainda é "classe em si" e "classe para si". O tempo todo Marcelo Badaró

3 Ibidem, p. 123. 
Mattos nos lembra que essa classe é algo concreto, existente nas relações sociais do mundo real. Ela se organiza enquanto sujeito coletivo e atua politicamente a partir de seus múltiplos projetos e visões de mundo, no processo de luta constante contra a classe dominante. Por tudo isso, assume a preocupação constante de questionar se a classe trabalhadora está sendo engessada na análise enquanto uma simples "categoria" ou se sua dimensão de sujeito histórico e político está sendo considerada. E o faz sem ignorar a diversidade interna à classe trabalhadora, atravessada por cor, etnia, gênero, sexualidade...

Recebido em 10/11/2019

Aprovado em 18/01/2020 